\title{
The Application of Fuzzy Delphi Method (FDM) For Evaluating The Factors Affecting Sustainable Tourism in Order To Develop A Model For Sustanable Tourism
}

\author{
Arian Dokht Farnad Pour \\ PhD (scholar), Faculty of Management Studies and Research AMU-ALIGARH
}

\begin{abstract}
Regarding with the effect of disease transmission and environmental pollution caused by passengers and immigrants' entrance on sustainable tourism and also considering the impact of medical tourism on sustainable tourism, in this chapter according to Sadler's Model, the researcher has designed a new model in which she added the health care as an effective factor on sustainable tourism and also s/he illustrated the significant role of information technology (as an influential factor) on all effective factors of sustainable tourism in the designed model. In this research Fuzzy Delphi Method (FDM) was used to obtain the critical factors of the sustainable tourism by seeking opinion of tourism experts to establish a new model for sustainable tourism.
\end{abstract}

Keywords: sustainable tourism, Fuzzy Delphi Method (FDM),information and communication technology (ICT), healthcare.

\section{Introduction}

Sustainable tourism cannot be discussed separately from the concept of sustainable development; therefore, the concept of sustainable development in the tourism sector can be explained in terms of macroeconomic concepts of sustainable development. Sustainable tourism emphasizes the need to use and develop tourism resources in wholesome routes (Hasanpourloumer, 2014). The underlying approach that is already used in tourism planning and other types of development is the approach of achieving sustainable development

Sadler was among the first who proposed the model for sustainable ecotourism model in 1990. He depicted three goals in his model social, economic and environmental goals they were. Social goals include the provision of social benefits, participation in planning, training and employment of local residents. Economic goals include economic benefits for local communities as well as sustainability in the economy of these regions. Environmental goals include the protection of natural resources, prevention of degradation and management of those resources. Sadler's model shows that the confluences of these goals indicate sustainable ecotourism (Sadler, 1990).

Figure 1 illustrates the challenge of applying the concept of sustainable development. The intersection of these circles represents the zone of sustainability. The present situation, illustrated by three circles of different sizes, reflects the importance currently placed on the three different dimensions of sustainable development.

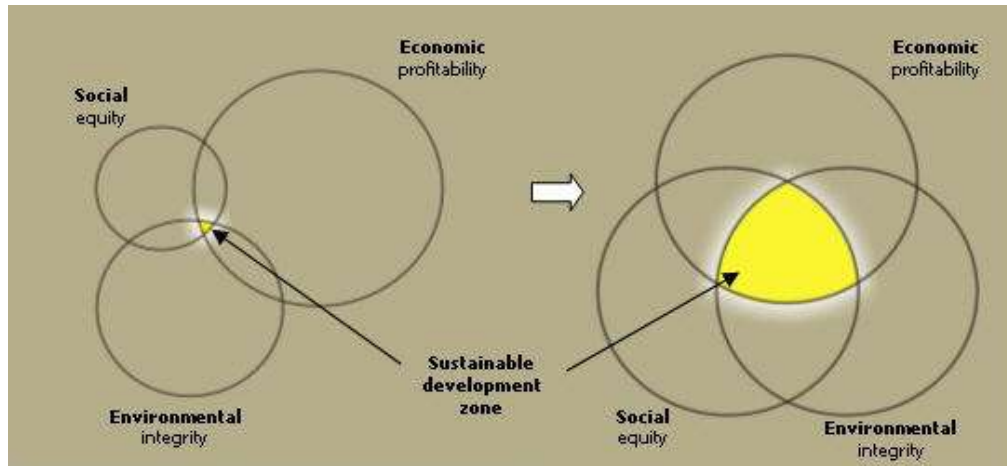

Figure 1: Sustainable Tourism Model

Source: Adapted from Jacob, P. and B. Sadler, 1990 and MENV, 2004.

Evaluation Model for Sustainable Tourism

Regarding with the effect of disease transmission and environmental pollution caused by passengers and immigrants' entrance on sustainable tourism and also considering the impact of medical tourism on sustainable tourism, in this chapter according to Sadler's Model, the researcher has designed a new model in 
which s/he added the health care as an effective factor on sustainable tourism and also s/he illustrated the significant role of information technology (as an influential factor ) on all effective factors of sustainable tourism in the designed model. This signifies that adding healthcare as the effective factor on sustainable tourism, not only causes implementation of policies for avoiding transmission of diseases and pollution caused by tourist to the touristic area but it is also spreads awareness among tourists regarding diseases and possible and popular pollutions in the area for the sake of tourists themselves and for maintaining a sustainable tourism. In this research FUZZY DELPHI METHOD (FDM) was used to obtain the critical factors of the sustainable tourism by seeking opinion of tourism experts to establish a new model for sustainable tourism. (Figure 2)
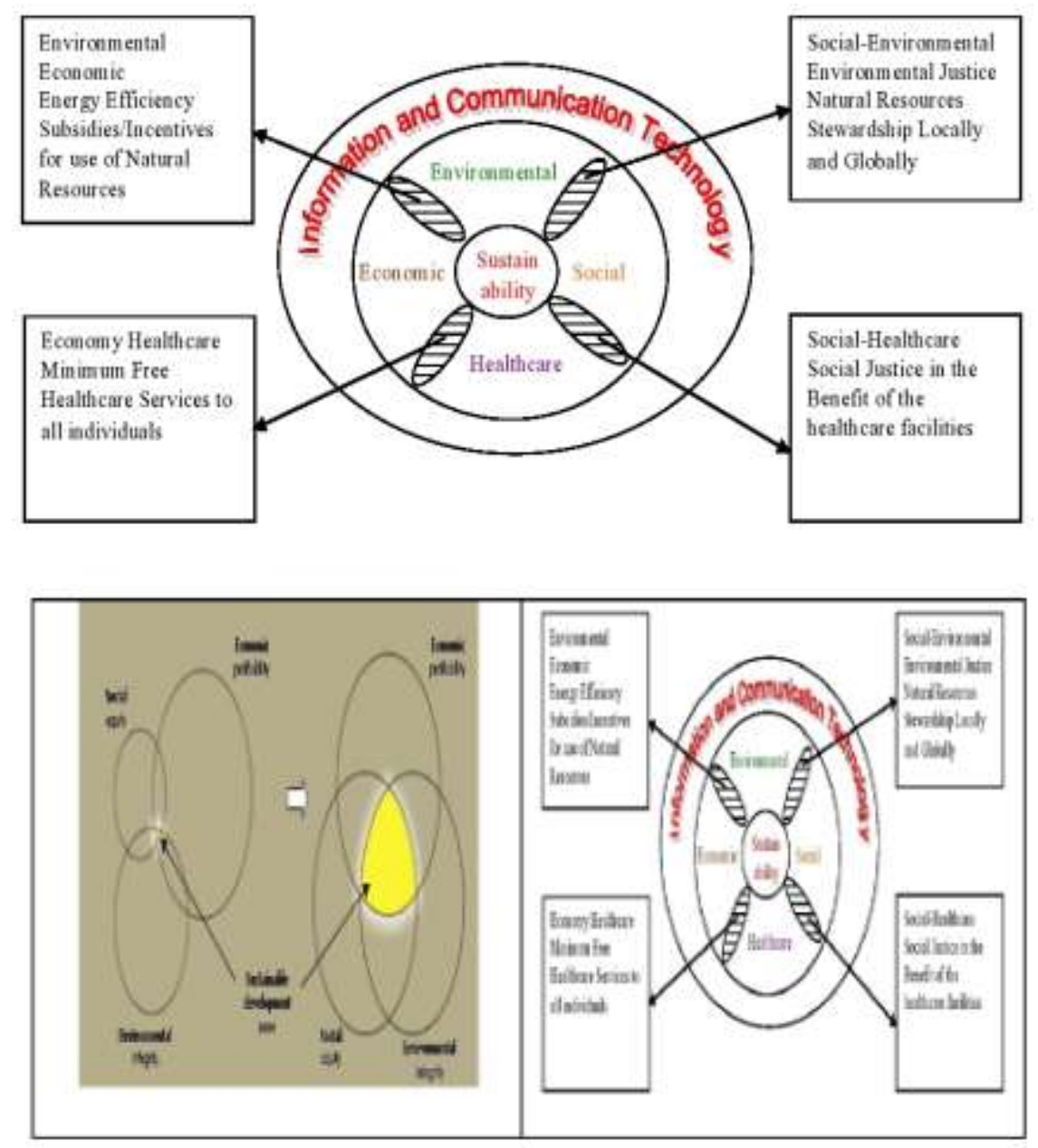

Figure 2: New Sustainable tourism model

Source: Developed by researcher

\section{Validity and Reliability Validity}

Validity can be defined as the degree to which a test measures what it is supposed to measure. There are three basic approaches to the validity of tests and measures as shown by Mason and Bramble (1989).

The validity for questionnaire is obtained by KMO and Bartlett's Test by SPSS19 software.

\section{Reliability}

Reliability of questionnaire is obtained by Cronbach's Alpha Test by SPSS19 software. (Reliability in this part of the study, this coefficient of 0.696 the higher is the minimum acceptable)

\section{The Research Methods}

The study is to establish the key parameters for evaluation of the sustainable tourism analyzing, and use FDM by consulting and employing twenty Tourism experts in the ministry of tourism, New Delhi and academician in jamia milliai slamia and Delhi University formed the population. Out of this ten academicians and ten experts from ministry of tourism were selected for the study based on the judgment of Researcher in 
order creation a model for sustainable tourism in order to find out the important factors to be conceded.

The survey methodology was used to gather the data and to build the sustainable tourism criteria. Before designing the survey, the researcher gathered the evaluation criteria from literature studies and some expert idea. Beside, according the literatures, researcher combined the criteria of sustainable tourism elements and prior researches in related or other arenas and generalized 74 factors of which 68 selected as important constructs five important aspects in all they were 74 parameters in the first round and 68 parameters in the second round, respectively five point Likert scale was used of the study. Where in 5 indicated. Strongly disagree, disagree, neutral, agree, and strongly agree.

\section{Fuzzy Delphi Method}

Fuzzy Delphi Method was proposed by Ishikawa et al. (1993), and it was derived from the traditional Delphi technique and fuzzy set theory. Noorderhaben (1995) indicated that applying the Fuzzy Delphi Method to group decision can solve the fuzziness of common understanding of expert opinions. As for the selection of fuzzy membership functions, previous researches were usually based on triangular fuzzy number, trapezoidal fuzzy number and Gaussian fuzzy number. This study applied the triangular membership functions and the fuzzy theory to solving the group decision. This study used FDM for the screening of alternate factors of the first stage. The fuzziness of common understanding of experts could be solved by using the fuzzy theory, and evaluated on a more flexible scale. The efficiency and quality of questionnaires could be improved. Thus, more objective evaluation factors could be screened through the statistical results (L.A. Zadeh, 1965) (R.Zhau, R. Goving,1991).

The FDM steps are as follows:

1. Collect opinions of decision group: Find the evaluation score of each alternate factor's significance given by each expert by using linguistic variables in questionnaires.

2. Set up triangular fuzzy numbers: Calculate the evaluation value of triangular fuzzy number of each alternate factor given by experts, find out the significance triangular fuzzy number of the alternate factor.

This study used the geometric mean model of mean general model proposed by Klir and Yuan (1995) for FDM to find out the common understanding of group decision. The computing formula is illustrated as follows:

Assuming the evaluation value of the significance of

No. $\mathrm{j}$ element given by No. $\mathrm{i}$ expert of $\mathrm{n}$ experts is

$w_{i j}\left(a_{i j}, b_{i j}\right), i=1,2, \ldots, n ; j=1,2, \ldots, m$. Then the

fuzzy weighting $w_{j}$ of No. $j$ element is $w_{j}\left(a_{j}, b_{j}, c_{j}\right)$,

$\mathrm{j}=1,2, \ldots, \mathrm{m}$

$\mathrm{a}_{\mathrm{j}=} \operatorname{Min}_{\mathrm{i}}\left(\mathrm{a}_{\mathrm{ij}}\right), \mathrm{b}_{\mathrm{j}}=\frac{1}{n} \sum_{\mathrm{i}=1}^{n}$ bij, $\mathrm{c}_{\mathrm{j}}=\operatorname{Max}_{\mathrm{i}}\left(\mathrm{c}_{\mathrm{ij}}\right)$

3. Defuzzification: Use simple centre of gravity method to defuzzify the fuzzy weight $\mathrm{w}_{\mathrm{j}}$ of each

alternate element to definite value $S_{\mathrm{j}}$, the followings

are obtained:

$\mathrm{S}_{\mathrm{j}}=\frac{\mathrm{aj+bj+cj}}{3} \quad \mathrm{j}=1,2, \ldots, \mathrm{m}$

4. Screen evaluation indexes: Finally proper factors can be screened out from numerous factors by setting the threshold a. The principle of screening is as follows:

If $\mathrm{Sj} \geq$, ahen No. $\mathrm{j}$ factor is the evaluation

index.If $S_{j}<\alpha$, then delete No. $\mathrm{j}$ factor. Schematic diagram of Fuzzy Delphi Method threshold is shown in Fig. 6.3

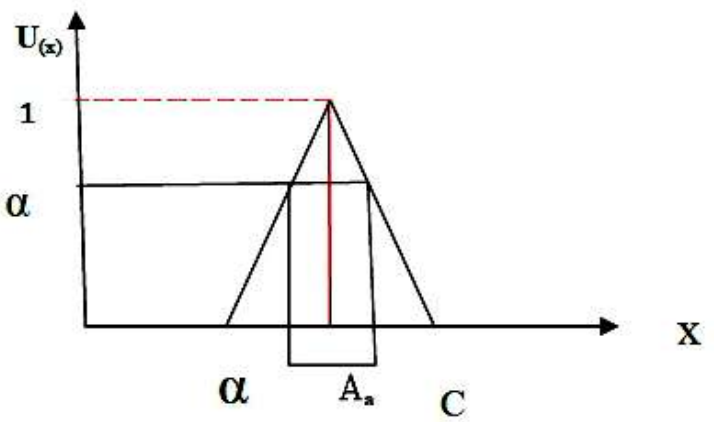

Figure 3: schematic diagram of Fuzzy Delphi 
To collect the fuzzy numbers which have derived from directly from expert idea, In this study we have

(5) $\mathrm{Aij}=[\alpha \mathrm{ij}], \alpha \mathrm{ij} \times \alpha \mathrm{ji} \approx 1, \quad \forall \mathrm{i}, \mathrm{j}=1,2,3 \ldots \ldots$

To calculate the fuzzy relative weight we have used the following relations numbers (6), (7) and (8):

(6) $\quad \alpha i j \otimes \ldots \ldots-\alpha i j]$

(7) $\mathrm{Zi}=\left[\alpha \mathrm{ij} \otimes \ldots \ldots . . \alpha_{\mathrm{ij}}\right]^{-1}$

(8) $\mathrm{Wi}=\mathrm{Zi} \otimes(\mathrm{Zi} \oplus \ldots \ldots \oplus \mathrm{Zn})$

6. Defuzzification: Convert fuzzy numbers to easy-comprehended definite values, this study adopts the geometric mean method to solve fuzzy numbers proposed by Liu and Chen, (2007), according torelation number :

used triangular method therefore a fuzzy number s defined according relations numbers

(1) to (4):

(1) $\quad \alpha$ ij $=(\alpha i j, d i j, g i j)$

(2) $\alpha i j=\operatorname{Min}($ bijk) $, k=1, \ldots . n$

(3) $\mathbf{d i j}=\left(\Pi^{n} \quad \text { bijk }\right)^{1 / \mathrm{n}}, \mathrm{k}=1, \ldots, \mathrm{n}$

(4) $\mathbf{g i j}=\operatorname{Max}(\mathrm{bijk}), \mathrm{k}=1, \ldots, \mathrm{n}$

Fig. 2 shows a typical fuzzy number which we have used in this study:

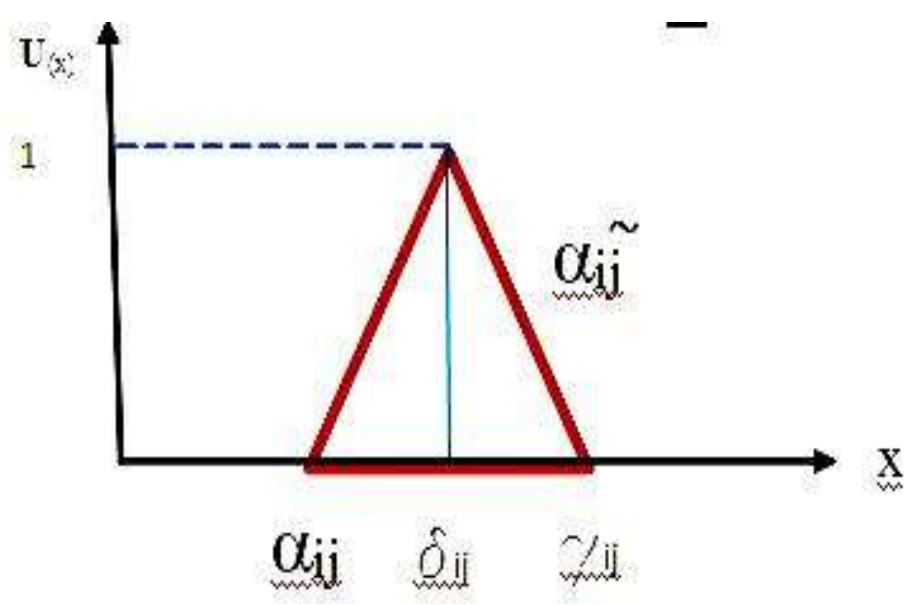

Figure 4: schematic diagram of Fuzzy Delphi method

Source: liu and chen, 2007

In which bijk is the relative preference parameter

"i" to parameter "j" from expert "k" view, aij and gij are the lower and upper limits of expert view, respectively and dij is the geometric mean of experts views. Therefore parameters are so defined that: $\alpha \mathrm{ij} \leq \mathrm{dij} \leq \mathrm{gij}$

Then according to calculated fuzzy numbers as mentioned above, paired matrices between various parameters the inverted matrices are set up for fuzzy numbers according relation (5):

(5) $\mathrm{Aij}=[\alpha \mathrm{ij}], \alpha \mathrm{ij} \times \alpha \mathrm{ji} \approx 1, \forall \forall_{\mathrm{i}, \mathrm{j}=1,2,3 \ldots \ldots}$

To calculate the fuzzy relative weight we have used the following relations numbers (6), (7) and (8):
(6),$\alpha i j \otimes \ldots \ldots-\alpha i j]$
(7) $\mathrm{Zi}=[\alpha \mathrm{ij} \otimes \ldots \ldots . \otimes \alpha \mathrm{ij}]^{-1}$
(8) $\mathrm{Wi}=\mathrm{Zi} \otimes(\mathrm{Zi} \oplus \ldots \ldots \oplus \mathrm{Zn})$

6)Defuzzification: Convert fuzzy numbers to easy-comprehended definite values, this study adopts the geometric mean method to solve fuzzy numbers proposed by Liu and Chen, (2007), according to relation number:

2. (9), $\mathrm{Wi}=($ 
7. Sequencing: Sequence defuzzified criteria.

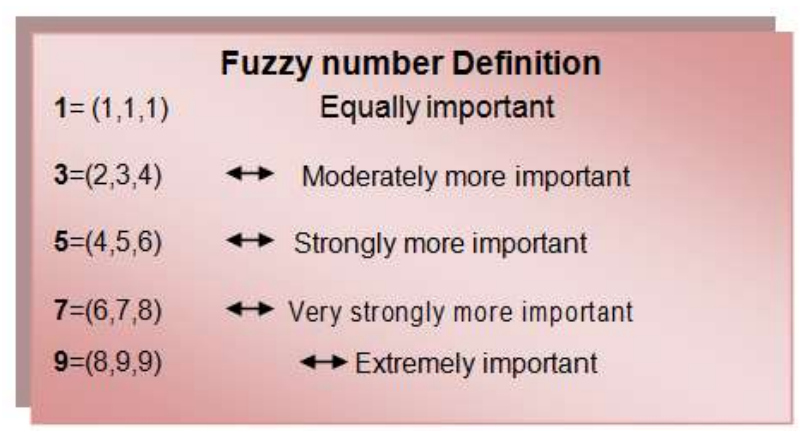

Table 1 : Fuzzy number Definition

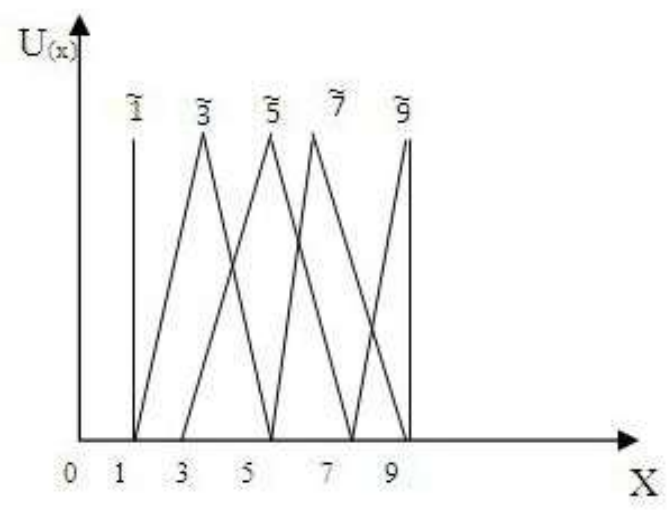

Figure 5: Scale of fuzzy numbers

Evaluating model Application and Results

A) Reviewing relevant literature of Sustainable tourism Investigation and proposing important criteria: More than 74 criteria (Parameter) for Sustainable tourism Investigation based on reviewing relevant literature and adopted Table 2

Table 6 : 74 Criteria (Parameter) for Sustainable tourism

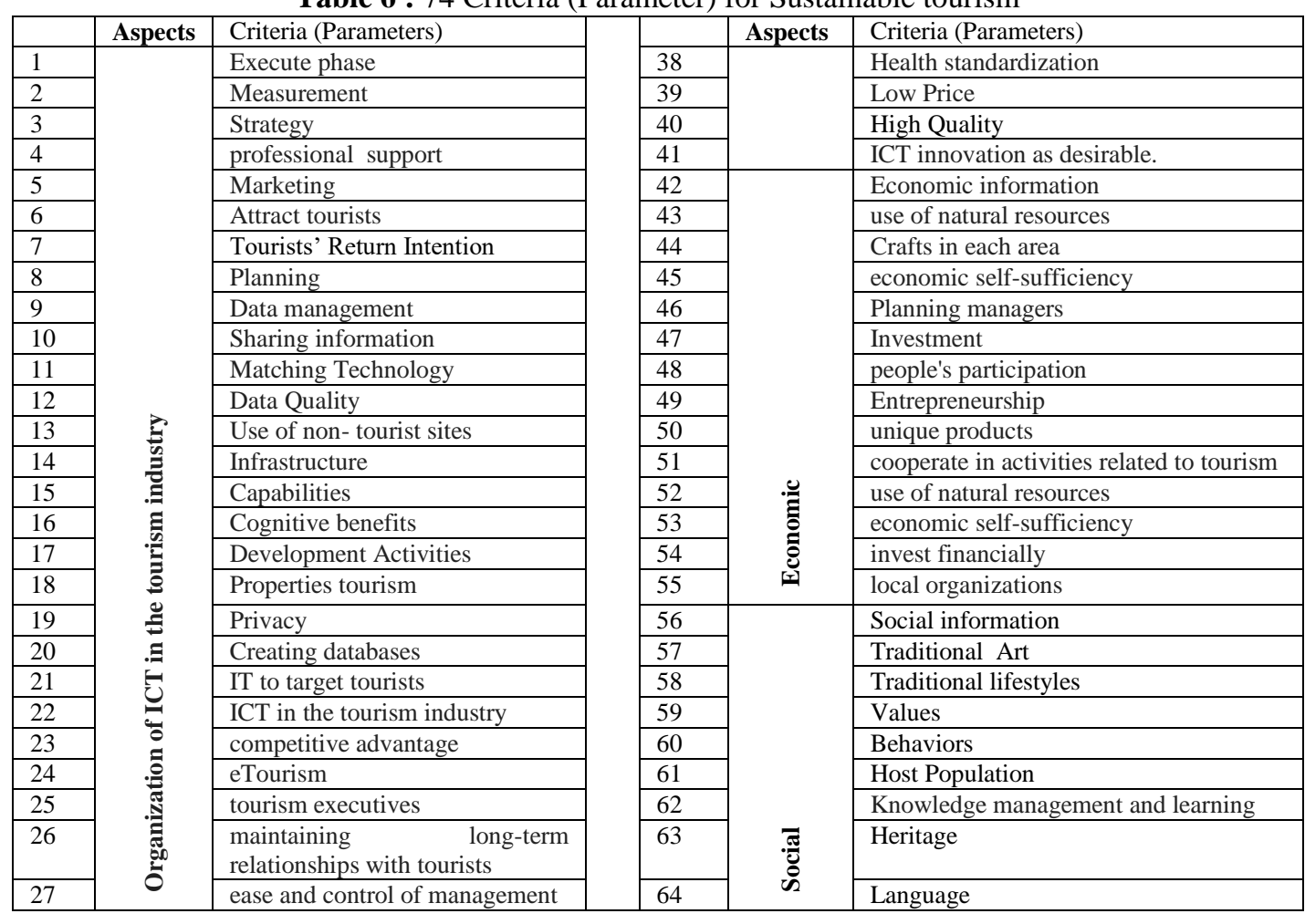


The Application of Fuzzy Delphi Method (FDM) For Evaluating The Factors Affecting Sustainable ...

\begin{tabular}{|c|c|c|c|c|c|}
\hline 28 & & Management support & 65 & & Religion \\
\hline 29 & & respect and care for the tourists. & 66 & & Environmental information \\
\hline 30 & & 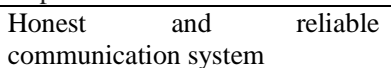 & 67 & & environmental protection \\
\hline 31 & & needs of tourists & 68 & & $\begin{array}{l}\text { environmental and social baseline } \\
\text { studies }\end{array}$ \\
\hline 32 & \multirow{6}{*}{ 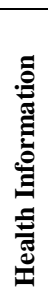 } & health information & 69 & & negative impacts of tourism \\
\hline 33 & & $\begin{array}{l}\text { health information infrastructure } \\
\text { undermines }\end{array}$ & 70 & \multirow{5}{*}{ 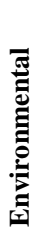 } & Natural resources \\
\hline 34 & & controlling healthcare & 71 & & Visual impact \\
\hline 35 & & improving health services & 72 & & Urban form \\
\hline 36 & & $\begin{array}{l}\text { sharing of medical information } \\
\text { online }\end{array}$ & 73 & & Infrastructure \\
\hline 37 & & $\begin{array}{l}\text { control of communicable } \\
\text { diseases and epidemics }\end{array}$ & 74 & & Restoration \\
\hline
\end{tabular}

\section{B) Screen important criteria (Parameters) by Fuzzy Delphi Method.}

This stage includes three sections. Firstly, it lists five main aspects and 74 items as the key evaluation items of Sustainable tourism Investigation, and a FDM interview framework is set up. The second section is the interview with twenty experts from the academic community in India. Delphi Method mostly aims at easy common understanding of group opinions through twice provision of questionnaires.

FDM formed by adding the fuzzy theory in, not only maintains the advantage of Delphi Method, but also reduces the provision times of questionnaires when using traditional Delphi Method as well as the cost.

For the third section, the opinions of experts in FDM questionnaires are converted to triangular fuzzy numbers, and defuzzified values can be figured out after calculation. This stage adopts elements with threshold above 6 , and the key evaluation items with threshold below 6 are deleted. The important evaluation items after screening are listed in Table 3

Table 3: New evolution Criteria after Fuzzy Delphi Method

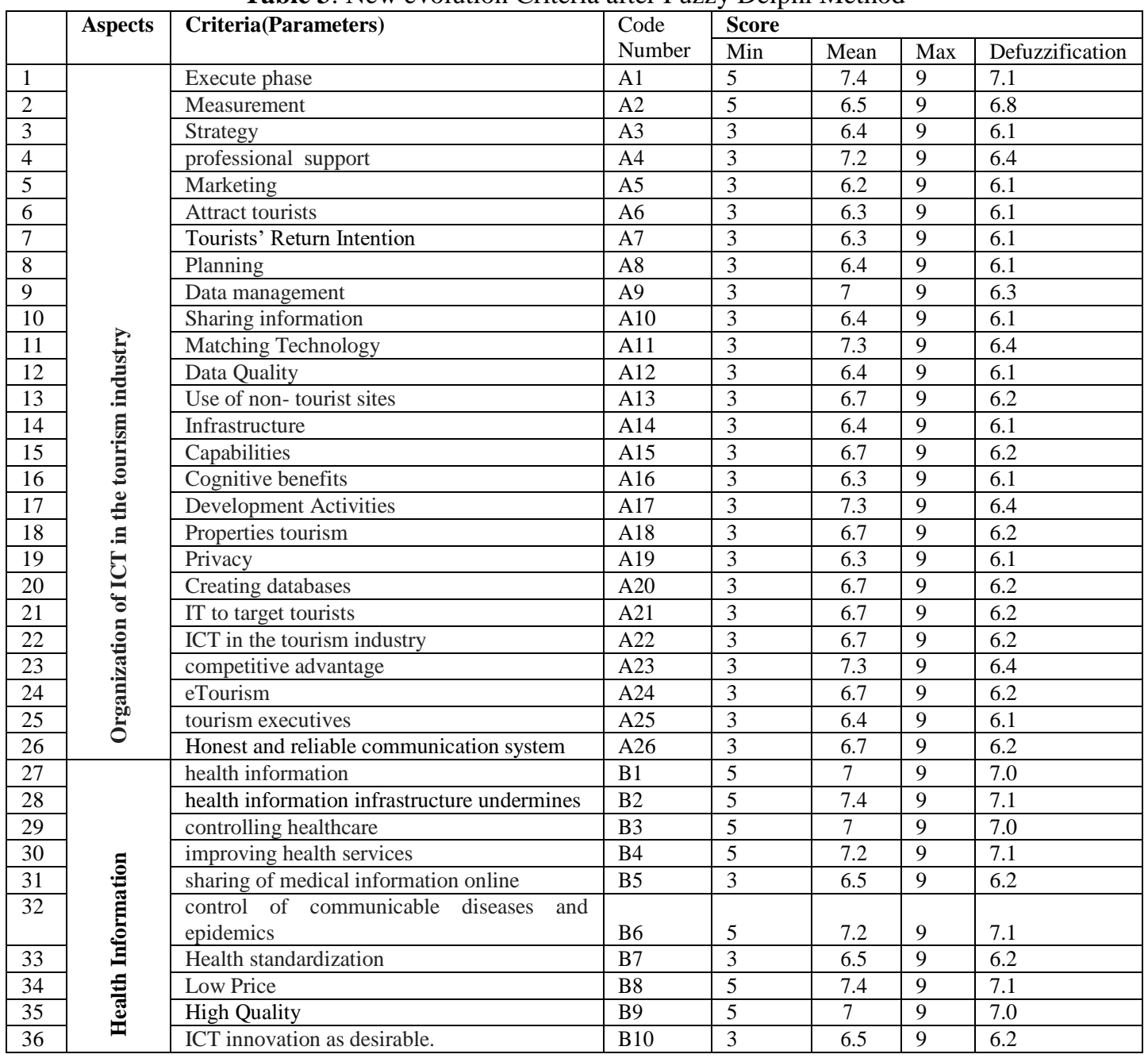


The Application of Fuzzy Delphi Method (FDM) For Evaluating The Factors Affecting Sustainable ...

\begin{tabular}{|c|c|c|c|c|c|c|c|}
\hline 37 & \multirow{14}{*}{ 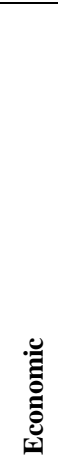 } & Economic information & $\mathrm{C} 1$ & 5 & 6.7 & 9 & 6.9 \\
\hline 38 & & use of natural resources & $\mathrm{C} 2$ & 5 & 6.8 & 9 & 6.9 \\
\hline 39 & & Crafts in each area & $\mathrm{C} 3$ & 5 & 6.2 & 9 & 6.7 \\
\hline 40 & & economic self-sufficiency & $\mathrm{C} 4$ & 5 & 6.6 & 9 & 6.9 \\
\hline 41 & & Planning managers & $\mathrm{C} 5$ & 5 & 6.5 & 9 & 6.8 \\
\hline 42 & & Investment & C6 & 5 & 6.8 & 9 & 6.9 \\
\hline 43 & & people's participation & $\mathrm{C7}$ & 5 & 7.2 & 9 & 7.1 \\
\hline 44 & & Entrepreneurship & $\mathrm{C} 8$ & 3 & 6.5 & 9 & 6.2 \\
\hline 45 & & unique products & $\mathrm{C} 9$ & 5 & 6.7 & 9 & 6.9 \\
\hline 46 & & cooperate in activities related to tourism & C10 & 5 & 6.6 & 9 & 6.9 \\
\hline 47 & & use of natural resources & $\mathrm{C} 11$ & 5 & 6.5 & 9 & 6.8 \\
\hline 48 & & economic self-sufficiency & $\mathrm{C} 12$ & 5 & 7.4 & 9 & 7.1 \\
\hline 49 & & invest financially & $\mathrm{C} 13$ & 5 & 7 & 9 & 7.0 \\
\hline 50 & & local organizations & $\mathrm{C} 14$ & 3 & 6.5 & 9 & 6.2 \\
\hline 51 & \multirow{9}{*}{ } & Social information & D1 & 7 & 8.4 & 9 & 8.1 \\
\hline 52 & & Traditional Art & D2 & 5 & 7 & 9 & 7.0 \\
\hline 53 & & Traditional lifestyles & D3 & 5 & 7.1 & 9 & 7.0 \\
\hline 54 & & Values & D4 & 5 & 7.6 & 9 & 7.2 \\
\hline 55 & & Behaviors & D5 & 5 & 7.5 & 9 & 7.2 \\
\hline 56 & & Host Population & D6 & 5 & 7.5 & 9 & 7.2 \\
\hline 57 & & Knowledge management and learning & D7 & 5 & 6 & 9 & 6.7 \\
\hline 58 & & Heritage & D8 & 3 & 6.5 & 9 & 6.2 \\
\hline 59 & & Language & D9 & 5 & 7.5 & 9 & 7.2 \\
\hline 60 & \multirow{9}{*}{ 栉 } & Environmental information & E1 & 5 & 7.1 & 9 & 7.0 \\
\hline 61 & & environmental protection & E2 & 5 & 7.1 & 9 & 7.0 \\
\hline 62 & & environmental and social baseline studies & E3 & 5 & 6.5 & 9 & 6.8 \\
\hline 63 & & negative impacts of tourism & E4 & 5 & 6 & 9 & 6.7 \\
\hline 64 & & Natural resources & E5 & 5 & 7.1 & 9 & 7.0 \\
\hline 65 & & Visual impact & E6 & 5 & 7.6 & 9 & 7.2 \\
\hline 66 & & Urban form & E7 & 5 & 6.6 & 9 & 6.9 \\
\hline 67 & & Infrastructure & E8 & 5 & 6.5 & 9 & 6.8 \\
\hline 68 & & Restoration & E9 & 3 & 6.5 & 9 & 6.2 \\
\hline
\end{tabular}

C) Design model based on factors approved by experts.

The Sustainable tourism Investigation can be evaluated based on five evaluation aspects and 68 evaluation criteria or Parameters and Therefore, the model proposed by the researchers taking into account 68 parameters in 5 aspects and one purpose was approved by experts.

\section{Conclusions}

Reviewing relevant literature of sustainable tourism and investigation and proposing important criteria: (More than 74 criteria Parameter) for Sustainable tourism Investigation based on reviewing relevant literature and adopted Table 6.2B) Screen important criteria (Parameters) by Fuzzy Delphi Method. This stage includes three sections. Firstly, it lists five main aspects and 74 items as the key evaluation items of sustainable tourism Investigation, and a FDM interview framework is set up. The second section is the interview with twenty experts from the academic community in India. Delphi Method mostly aims at easy common understanding of group opinions through twice provision of questionnaires.

FDM formed by adding the fuzzy theory in, not only maintains the advantage of Delphi Method, but also reduces the provision times of questionnaires when using traditional Delphi Method as well as the cost. For the third section, the opinions of experts in FDM questionnaires are converted to triangular fuzzy numbers, and defuzzified values can be figured out after calculation. This stage adopts elements with threshold above 6 , and the key evaluation items with threshold below 6 are deleted. The Sustainable tourism Investigation can be evaluated based on five evaluation aspects and 68 evaluation criteria or Parameters and Therefore, the model proposed by the researchers taking into account 68 parameters in 5 aspects and one purpose was approved by experts.

\section{References}

[1] Hasanpourloumer, S \&SattariSarebangholi, H \&Toofan, S. 2014. Designing the Residential Places for Tourists Based on Environmental Factors and Green Architecture: A Case Study in Historical City of Masouleh. European Online Journal of Natural and Social Sciences.Vol 3: 39-46.

[2] L. A. Zadeh, Fuzzy sets, Information Control, 8 (1965) 338-353. http://dx.doi.org/10.1016/S0019-9958(65)90241 X -

[3] R. Zhau, R. Goving, Algebraic characteristics of extended fuzzy numbers, Information Science, 54 (1991) 103-130. http://dx.doi.org/10.1016/0020-0255(91)90047-X

[4] Sadler, B .1990. Sustainable Development, Northern Realities and the Design and Implementation of Regional Conservation Strategies, in Achieving Sustainable Development through Northern Conservation Strategies, Calgary, Alberta: University of Calgary Press. 